\title{
Dopaminergic modulation of the persistence of one-trial hippocampus-dependent memory
}

\author{
Colin M. O'Carroll, ${ }^{1,4}$ Stephen J. Martin, ${ }^{1}$ Johan Sandin, ${ }^{2}$ Bruno Frenguelli, ${ }^{3}$ \\ and Richard G.M. Morris ${ }^{1,5}$ \\ ${ }^{1}$ Laboratory for Cognitive Neuroscience, Centre for Cognitive and Neural Systems, The University of Edinburgh, Edinburgh EH8 \\ 9JZ, United Kingdom; ${ }^{2}$ Translational Pharmacology, Department of Disease Biology, Astra Zeneca, SE-151 85 Södertälje, Sweden; \\ ${ }^{3}$ Division of Pathology and Neuroscience, University of Dundee, Ninewells Hospital and Medical School, Dundee DD1 9SY, \\ United Kingdom
}

\begin{abstract}
The persistence of new memory traces in the hippocampus, encoded following appropriate activation of glutamatergic receptors and the induction of synaptic plasticity, can be influenced by heterosynaptic activation of neuromodulatory brain systems. We therefore investigated the effects of a hippocampus-specific blockade of dopamine DI/D5 receptors on the persistence of spatial memory encoded in one trial using a delayed matching-to-place (DMP) task in a watermaze in which rats learn a new escape location each day. A within-subjects design was used such that both short $(20 \mathrm{~min})$ and long $(6 \mathrm{~h})$ retention intervals, and both drug (SCH23390, a D1/D5 receptor antagonist) and vehicle (aCSF) infusions were tested on different days in the same animals. Bilateral intrahippocampal infusion of SCH23390 (5 $\mu \mathrm{g}$ in $1 \mu \mathrm{L}$ per side) prior to trial 1 (encoding) caused a differential impairment as a function of memory delay-with no effect during trial 2 (memory retrieval) after a 20-min interval, but a block of memory at $6 \mathrm{~h}$. Further experiments revealed that infusion of SCH23390 immediately after trial 1 had no effect on retention $6 \mathrm{~h}$ later, and the poor memory seen at long retention intervals when the drug was present at encoding was not due to a state-dependent failure of retrieval. These results suggest that activation of D1/D5 receptors during memory encoding is necessary for the formation of a persistent memory trace in the hippocampus. The complementary effects of D1/D5 receptor blockade on the persistence of LTP and the duration of memory are consistent with the idea that changes in synaptic strength underlie memory.
\end{abstract}

The persistence of memory encoded by the hippocampal formation is subject to heterosynaptic neuromodulatory signals from a number of cortical and subcortical structures. The hippocampus receives dopaminergic projections from mesolimbic structures such as the ventral tegmental area (VTA) and substantia nigra (Carter and Fibiger 1977; Scatton et al. 1980; Swanson 1982; Gasbarri et al. 1994a,b). These inputs may provide one neuromodulatory signal that could influence hippocampal memory, both in rodents (for review, see Gasbarri et al. 1997; Jay 2003) and in humans (e.g., Wittmann et al. 2005). The modulatory effect of dopamine, particularly under circumstances of novelty (see Lisman and Grace 2005), could give rise to either a selective strengthening of hippocampal memory traces or to an alteration in the persistence of such traces (or some combination of both effects). In the second case, neuromodulation acting at or around the time of learning might affect the process of "cellular consolidation" (Dudai and Morris 2001). Such modulation would be consistent with the known effects of activation of dopaminergic metabotropic receptors on postsynaptic intracellular signaltransduction pathways.

Within this general framework, it is of importance to ask about the conditions in which dopaminergic neurons are activated. Single-unit recording studies have revealed that burst firing of dopaminergic neurons is increased by unexpected reward and in association with stimuli that predict the imminent arrival of reward; such firing is also reduced when an expected reward is

\footnotetext{
4Present address: Roche Palo Alto LLC, Palo Alto, California 94304, USA. ${ }^{5}$ Corresponding author.

E-mail r.g.m.morris@ed.ac.uk; fax 44-131-650-4579.

Article is online at http://www.learnmem.org/cgi/doi/10.1101//m.321006.
}

omitted (e.g., Mirenowicz and Schultz 1994; Schultz and Dickinson 2000). These observations fit with computational models that assign a key role for dopamine neurons in signaling any discrepancy between predicted and received reward (Montague et al. 1996). However, the firing rates of ventral tegmental area dopaminergic neurons are also increased by exposure to novel stimuli (Steinfels et al. 1983; Ljungberg et al. 1992). Thus, while the role in reward processing is now well established for the striatum, dopamine may have diverse functions that depend on the brain region in which its release occurs. The focus of the present work is its impact on hippocampal function. The observations that hippocampal lesions disrupt the detection of certain kinds of mismatch between stored and incoming information (ThinusBlanc et al. 1991; Fyhn et al. 2002), and that haemodynamic activation of the human hippocampus is seen during the observation of novel stimuli (Tulving et al. 1994), collectively support the suggestion that this brain area is involved in the computation of novelty via "comparator" circuitry (Gray and McNaughton 2000; Vinogradova 2001). Other brain areas also detect other kinds of novelty (Aggleton and Brown 1999). Once information has been identified as novel, a signal may be carried from the hippocampus (or other brain areas) through a polysynaptic pathway (involving the subiculum, nucleus accumbens, and ventral pallidum) to the VTA (see Lisman and Grace 2005). The noveltyassociated firing of dopaminergic VTA neurons could then lead to dopamine release in various forebrain regions, including feedback regulation of the hippocampus itself.

What might be the impact of dopamine release in hippocampus? There is growing physiological evidence for dopaminergic involvement in the late, protein synthesis-dependent phase of long-term potentiation (Frey et al. 1990, 1991; Matthies et al. 
1997; Swanson-Park et al. 1999; O'Carroll and Morris 2004) and in local dendritic protein synthesis (Smith et al. 2005). However, a small effect of dopamine D1/D5 receptor blockade on early-LTP is commonly observed and dopamine D1/D5 receptor agonists can enhance the magnitude of CA1 early-LTP (Otmakhova and Lisman 1996) and dentate gyrus LTP in anesthetized rats, induced using a weak tetanus (Kusuki et al. 1997). Brief exposure to a novel environment can also facilitate the induction of CA1 LTP by a subsequent weak tetanus; this facilitation is selectively blocked by a D1/D5 receptor antagonist, and mimicked by the application of an agonist (Li et al. 2003). It follows that, if LTPlike potentiation is part of the mechanisms of memory trace formation, dopamine release could modulate the persistence or the strength of hippocampus-dependent memory, or have both effects.

Several rodent studies have directly implicated hippocampal dopamine receptors in memory, commensurate with their involvement in LTP. For example, intrahippocampal infusion of D1 or D2 receptor agonists can improve retention in radial maze working memory tasks (Packard and White 1991; Wilkerson and Levine 1999), and systemic infusion of a D1/D5 agonist improves spatial memory in aged mice (Bach et al. 1999). Conversely, intrahippocampal blockade of D1/D5 receptors can disrupt the consolidation of inhibitory avoidance (Bernabeu et al. 1997). While spatial reference memory in the watermaze is unaffected by 6-hydroxydopamine infusion into the neostriatum (Hagan et al. 1983), it is impaired by such infusions into the nigrostriatal bundle or lateral ventricles (Whishaw and Dunnett 1985) or directly into the subiculum and adjacent CA1 (Gasbarri et al. 1996). Genetic deletion of D1 receptors in mice can also impair spatial memory (El-Ghundi et al. 1999). These studies are suggestive, but the precise role of dopaminergic manipulations on strength versus persistence of memory has not been explicitly addressed.

Accordingly, in the experiments reported here we investigated the impact of blockade of dopamine receptors in the hippocampus with the D1/D5 receptor antagonist $\mathrm{SCH} 23390$ in a delayed matching-to-place (DMP) task in the watermaze. The DMP version of the watermaze (Steele and Morris 1999) is a repeated one-trial memory task that is very sensitive to hippocampal dysfunction of various kinds and allows the use of withinsubject manipulations across successive days of training with the inclusion of a variable memory delay. In this variant, the hidden platform is always in a "novel" location on the first trial of each day, and remains in a fixed location for the subsequent trials of that day (i.e., trials 2, 3 and 4). Trial 2 serves as a memory retrieval trial to investigate the strength or persistence of memory encoded in trial 1. Trials 3 and 4 serve only to sustain the win-stay strategy of swimming back to the place in the pool where escape has been possible most recently. The cycle of four trials repeats across days. We hypothesized that dopaminergic neurons would be activated by the unexpected reward of finding an escape platform in a novel location during the daily first trial of this task. This should in turn activate metabotropic D1/D5 receptors in the hippocampus and so result in either an enhancement of memory irrespective of the retention interval or an increase in the persistence of memory for spatial information (or both).

\section{Results}

A series of three experiments was conducted, consisting of "pretraining" on the DMP task (over $8 \mathrm{~d}$ ), during which the win-stay strategy was learned, followed by different drug-infusion and memory-delay conditions during a further series of eight "testing" days. As noted previously, the DMP task involves moving the hidden platform between separate locations across days, with varying intervals between trials 1 and 2 of each day (Fig. 1A). On a given day, the platform is placed in a novel location and then
A.

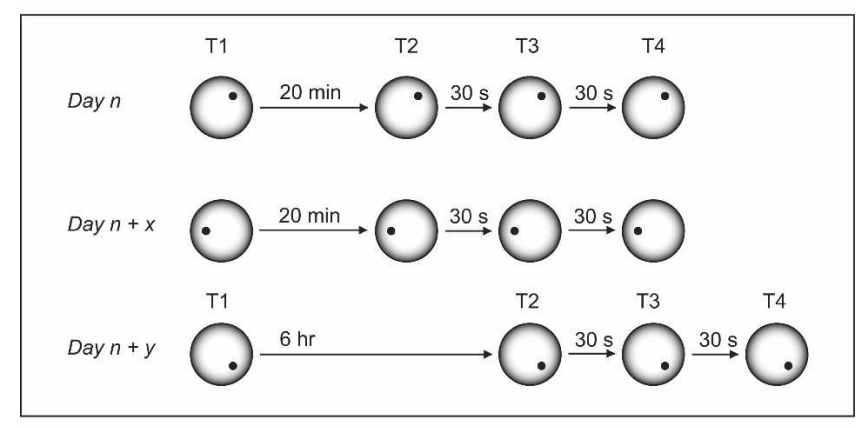

B.
1. Pretraining (all experiments): $\mathrm{T} 1$ to $\mathrm{T} 2$ interval $=20 \mathrm{~min}$ and $6 \mathrm{hr}$, no drugs - Fig 2
2. Experiment 1: $\mathrm{T} 1$ to $\mathrm{T} 2=20 \mathrm{~min}$ and $6 \mathrm{hr}$; drug infusions of aCSF or $\mathrm{SCH} 23390$ given 15 min before Trial 1 - Fig 3
3. Experiment 2: $\mathrm{T} 1$ to $\mathrm{T} 2=6 \mathrm{hr}$ always; drug infusions of aCSF or $\mathrm{SCH} 23390$ given 15 min after Trial 1 - Fig 4
4. Experiment 3: $\mathrm{T} 1$ to $\mathrm{T} 2=6 \mathrm{hr}$ always; drug infusions of aCSF or $\mathrm{SCH} 23390$ given 15 min before Trials 1 and 2 - Fig 4

Figure 1. Experimental design. $(A)$ Varied platform location and memory delay across days. All experiments used the delayed matchingto-place (DMP) protocol in the watermaze, in which four trials are given each day; the platform position is fixed within a day, but moved to different locations between days. Swim paths are circuitous in trial 1 of each day, but the focus is on whether memory traces formed during this trial persist with any detectable strength until trial 2 , which is scheduled after a variable delay. The point of trials 3 and 4 is to sustain the learned win-stay strategy that this protocol engenders. (B) Training conditions. There were three experiments, each preceded by a common set of $8 \mathrm{~d}$ of pretraining. Drugs were infused into the hippocampus at various times in relation to trials 1 and 2 as described.

stays there for all four trials. In Experiment 1, addressing the primary issue of memory strength vs. persistence, drug or vehicle was infused 15 min prior to trial 1 of the day (Fig. 1B), with the memory delay between trials 1 and 2 varying between 20 min and $6 \mathrm{~h}$. The interval between trials 2, 3, and 4 was always $30 \mathrm{sec}$ (spent on the escape platform). Experiment 2 was concerned with the impact of drug treatment after encoding, and so involved drug or vehicle being infused 15 min after trial 1 and a single 6-h memory delay. In Experiment 3, to test for statedependent effects, drug or vehicle was infused $15 \mathrm{~min}$ before trial 1 , and a second infusion-always of SCH23390-was made 15 min before trial 2 . Performance was compared with that on interleaved "no infusion" days during the testing sequence; a 6-h ITI between trials 1 and 2 was again used throughout. Whereas most watermaze studies plot performance across days (reference memory experiments), the DMP procedure focuses on changes within a day averaged across days.

\section{Pretraining: Acquisition of the DMP task}

During pretraining, all animals swam effectively using the usual posture of forepaw inhibition and learned to search for the hidden platform in trial 1 . They then found this location more quickly on subsequent trials. Overall performance improved during the first few days, typically reaching a stable asymptote by day 4 . Trial 1 was characterized by high escape latencies indicating the lack of knowledge of each day's novel platform position, but when placed back in the pool in trial 2, escape latencies were substantially reduced-reflecting the repeated acquisition of onetrial memory. Figure 2 shows the development of this matchingto-place performance over the course of pretraining in Experi- 


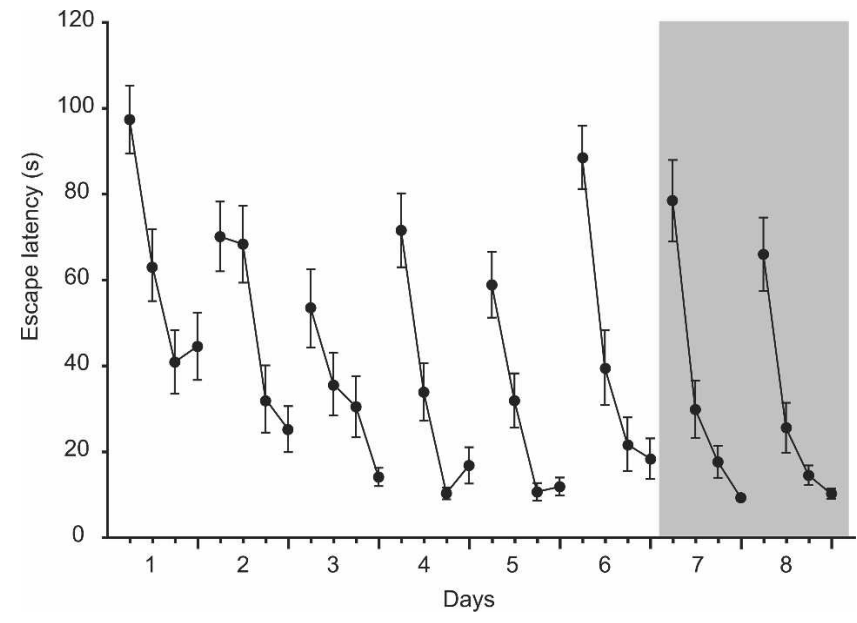

Figure 2. Pretraining. Acquisition of delayed matching-to-place. Absolute escape latency across the $8 \mathrm{~d}$ of pretraining during Experiment 1 . Note the gradual acquisition of an effective win-stay strategy characterized by, over the last $2 \mathrm{~d}$ (shaded), a striking reduction in escape latency between trials 1 and 2 of each day. Escape latency in trial 1 remains stable at ca $60 \mathrm{sec}$, reflecting the novel daily location of the hidden platform. Means \pm 1 SEM.

ment 1 , with particularly effective performance displayed during the last $2 \mathrm{~d}$ (shaded gray). The conventional measure of escape latency is plotted. On each day, the memory delay between trials 1 and 2 was $20 \mathrm{~min}$ for half the rats, and $6 \mathrm{~h}$ for the others. These intervals were counterbalanced across days, but pooled data are plotted in Figure 2. Mean savings in escape latency between trials 1 and 2 over the $8 \mathrm{~d}$ of pretraining did not differ between the two memory delays $(t=0.95, d f=22 ; P>0.3)$. Task acquisition followed a similar pattern in Experiments 2 and 3 (data not shown).

As the drug treatment in the test phase of each experiment affected swim speed, the remaining data is analyzed in terms of both swim speed and path length (rather than escape latency), in accordance with current convention regarding the optimum way to present watermaze data. To facilitate comparisons across experiments, a performance measure was also calculated, in which path lengths were normalized to the mean trial 1 path lengths in the appropriate control condition (i.e., no infusion, or $\mathrm{aCSF}=100 \%$ ). In this way, relative increases and decreases of path length induced by $\mathrm{SCH} 23390$ at various memory delays were readily observed, as well as absolute changes in path length in measures of savings.

\section{Experiment 1: A delay-dependent memory deficit following intrahippocampal infusions of SCH23390}

In Experiment 1, the testing phase was procedurally identical to pretraining, except that rats received a 5-min bilateral intrahippocampal infusion of either aCSF or SCH23390, finishing $15 \mathrm{~min}$ before trial 1 of each day (Fig. 1B). Figure 3A shows normalized path length across trials for the two memory delays after trial 1 ( $20 \mathrm{~min}$ on the left, $6 \mathrm{~h}$ on the right). For each animal, every combination of drug and ITI was repeated twice (see Materials and Methods). These two values were averaged for each of the four trials. Data were then averaged across all 23 rats, and a between-subjects standard error calculated, to produce each of the four acquisition curves shown in Figure 3A. Both SCH23390- and aCSF-treated rats exhibited good memory for the platform location in trial 2 after $20 \mathrm{~min}$, but the drug-treated group was impaired after a 6-h memory delay. An analysis of variance of path lengths in trials 1 and 2 revealed a significant triple interaction of trial, drug treatment, and memory delay $\left(F_{(1,22)}=4.90 ; P<0.05\right)$.
A separate ANOVA of performance at the 20-min delay revealed a significant overall improvement between trials 1 and 2 $\left(F_{(1,22)}=14.8 ; P=0.001\right)$, but no interaction between trial and drug treatment $\left(F_{(1,22)}=1.07 ; P>0.3\right)$. The trend toward a SCH23390-induced impairment in trial 2 did not reach significance $\left(F_{(1,22)}=3.13 ; 0.1>P>0.05\right)$. In contrast, at the $6-\mathrm{h}$ memory delay a highly significant interaction of trial and drug treatment was observed $\left(F_{(1,22)}=20.1 ; P<0.001\right)$. Whereas aCSFtreated rats improved between trials 1 and $2(t=4.04, d f=22$; $P=0.002)$, no change in performance between trials was evident following the administration of SCH23390 $(t=1.56, d f=22$; $P>0.2$ ).

A separate analysis was conducted of absolute savings in path length (in meters) between trials 1 and 2 as a function of memory delay ( $20 \mathrm{~min}$ or $6 \mathrm{~h}$ ). This also highlights the delaydependent effects of treatment with SCH23390 (see Fig. 3B). An overall ANOVA revealed a significant interaction between drug treatment and memory delay $\left(F_{(1,22)}=4.90 ; P<0.05\right)$. Performance was insensitive to delay following aCSF infusion $(t=0.85$, $d f=22 ; P>0.9)$ but significant delay-dependent forgetting was evident after treatment with SCH23390 $(t=3.04, d f=22$; $P<0.02)$. The savings in absolute path length in the two drug conditions did not differ at the 20-min interval $(t=1.04, d f=22$; $P>0.6$ ), but a clear difference was evident after a 6 h-delay $(t=4.48, d f=22 ; P<0.001)$. In fact, at a 6-h memory delay, the performance of SCH23390-treated rats did not differ from chance $(t=1.56, d f=22 ; P>0.1$; one-sample $t$-test $)$. Upon return to the short interval between trials 2 and 3 , and then 3 and 4 , the performance of the animals in the SCH23390 6-h delay condition reached levels equivalent to those of aCSF-treated controls $\left(F_{(1,22)}=2.74 ; P>0.1\right)$. This indicates that drug-treated animals were able to remember the position of the platform onto which they escaped in trial 2 (over $6 \mathrm{~h}$ after drug infusion) and so perform well in trials 3 and 4 .

Measurement of swim speed revealed a small but transient decline following treatment with SCH23390 (Fig. 3C). This effect appeared predominantly in trial 1, with little effect on subsequent trials, and sometimes resulted in slower swim speeds. An analysis of variance of swim speeds across all trials revealed a significant interaction between drug treatment and trial $\left(F_{(3,66)}=5.54 ; P<0.05\right)$. Pairwise comparisons showed that swim speeds were significantly lower in trial 1 following SCH23390 treatment, compared with aCSF $\left(F_{(1,22)}=35.8 ; P<0.001\right)$, further justifying our use of path length rather than escape latency for the main data measures. The impairment was short-lasting, with the difference in swim speed being no more than a trend in trial $2\left(F_{(1,22)}=4.30 ; 0.1>P>0.05\right)$.

\section{Experiment 2: SCH23390 has no effect on memory at a long delay when given after trial 1}

We then sought to establish whether the effect observed in Experiment 1 was due to a requirement for hippocampal dopamine receptor activation during the encoding of the novel platform position or during the subsequent processing of this information after acquisition. In Experiment 2, following the usual pretraining sessions (as shown in Fig. 2), the animals received a 5-min intrahippocampal infusion of either aCSF or SCH23390 between 10 and 15 min after trial 1 on each of the $8 \mathrm{~d}$ of further training. Only the 6-h memory delay was used.

The key finding was that when infused with SCH23390, the animals showed good memory for the platform location in trial 2 conducted $6 \mathrm{~h}$ later. Performance was indistinguishable from that shown by these same animals on aCSF-infusion days. Figure $4 \mathrm{~A}$ shows normalized path lengths averaged across the $4 \mathrm{~d}$ on which the relevant drug was administered. An analysis of vari- 
A.
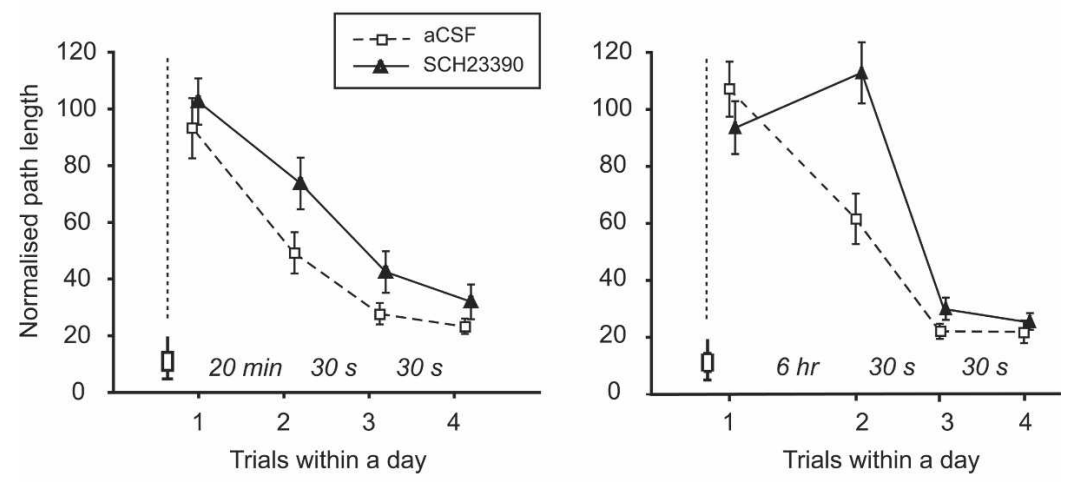

B.

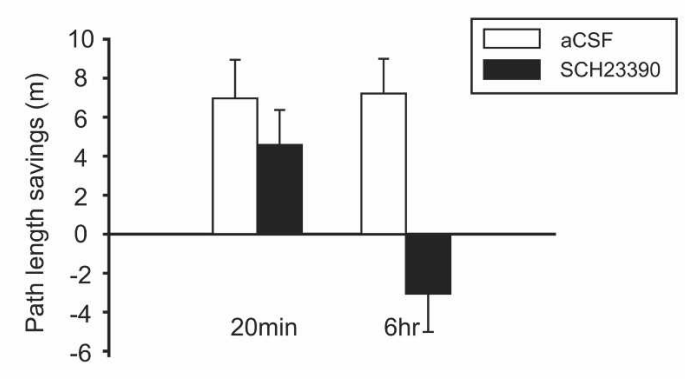

C.
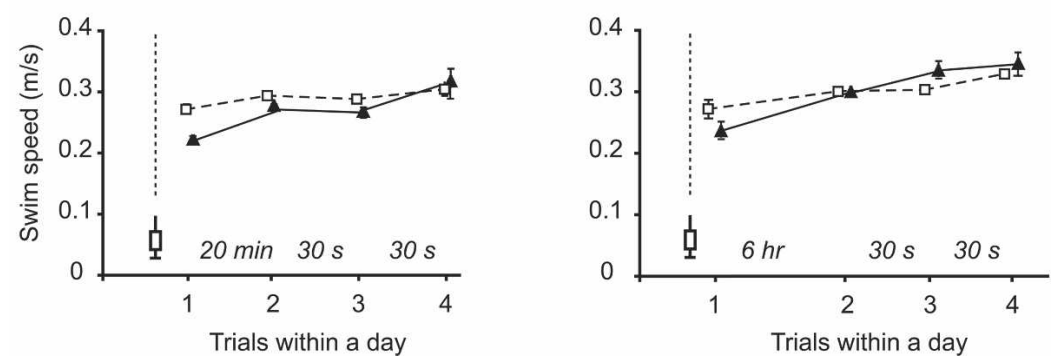

Figure 3. Experiment 1. (A) Drug injections prior to trial 1-impact of memory delay. Normalized path length averaged across days during the drug-infusion phase, showing performance across the four trials of each day $(n=23)$. A delay-dependent deficit is apparent, with the condition in which the animals received $\mathrm{SCH} 23390$ and a long memory delay resulting in no memory in trial 2 of each day. The syringes' symbols and dotted lines indicate the time of drug infusion. (B) Savings in path length between trials 1 and 2 . The change in performance between trials 1 and 2 (i.e., savings) is plotted in terms of absolute path length. These data show exactly the same pattern as in the normalized scores. (C) Swim speed. The drug did transiently decrease swim speeds, but the effect is only apparent in trial 1 of each day, scheduled 15 min after the intrahippocampal drug infusion. Means \pm 1 SEM.

ance of path lengths in trials 1 and 2 revealed no significant effect of drug treatment $(F<1)$, and no interaction between drug treatment and trial $(F<1)$. This finding is supported by an analysis of savings in path length between trials 1 and 2 for both groups. As shown in Figure 4B, there was no difference in savings between the SCH23390 and aCSF groups $(t=0.33, d f=7$; $P>0.7)$.

Normalization of path lengths offered the opportunity to compare across experiments. Path length in trial 2 of Experiment 2 , after a 6 -h ITI, was $\cong 60 \%$ of that in trial 1 for both the aCSF and SCH23390 conditions. In Experiment 1, the same value was obtained following aCSF infusions given prior to trial 1, whereas the SCH23390 condition was characterized by a much longer mean path length in trial $2(112 \%)$. Thus, there is a dramatically different effect of giving SCH23390 at a point $15 \mathrm{~min}$ before or 15 min after the memory-encoding trial on memory measured $6 \mathrm{~h}$ later.

\section{Experiment 3: Absence of state- dependent effects of SCH23390 on retention after a long delay}

State-dependent memory is a phenomenon in which the retrieval of information is possible only if the subject experiences the same sensory context and physiological state as that present during the encoding phase. One possible explanation for the drug-induced retrieval deficit observed in Experiment 1 at the 6-h interval is that the drug was no longer present when the rats were placed back into the pool in trial 2. In contrast, at the 20-min interval, the drug would almost certainly have been present in both trial 1 and trial 2, maintaining the same physiological state during both the encoding and retrieval phases of the experiment. Experiment 3 was conducted in order to address this alternative possibility; 15 min before trial 1 of each day, animals received an intrahippocampal infusion of either aCSF or SCH23390; a second infusion, always of SCH23390, was made $15 \mathrm{~min}$ prior to trial 2 (see Fig. 1B). The interval between trials 1 and 2 was always $6 \mathrm{~h}$. Days when animals had no infusions were interleaved between days with infusions to provide an internal within-subjects control for baseline performance on the task. A counterbalanced sequence of the two conditions continued for $8 \mathrm{~d}$.

The key finding was that when animals received intrahippocampal infusions of SCH23390 both $15 \mathrm{~min}$ before trial 1 and $15 \mathrm{~min}$ before trial 2, they showed poor memory (at $6 \mathrm{~h}$ ) for the platform location in trial 2 (Fig. 5A). However, when the animals were injected with aCSF 15 min before trial 1 , and then given SCH23390 before trial 2, retention was normal; performance was equivalent to that observed on the "no infusion" days. An ANOVA of performance in trials 1 and 2 revealed a significant interaction between treatment and trial $\left(F_{(2,14)}=5.14\right.$; $P<0.05)$, with no significant improvement between trials in the SCH23390/SCH23390 condition $(t=0.58, d f=7 ; P>0.9)$, but a significant reduction in path length on aCSF/SCH23390 $(t=3.64, d f=7 ; P<0.05)$. An ANOVA of savings data (Fig. 5B) revealed a main effect of drug treatment condition $\left(F_{(2,14)}=6.37\right.$; $P<0.02)$, with significantly higher savings in the aCSF/ SCH23390 condition relative to the SCH23390/SCH23390 condition $(t=5.94, d f=7 ; P=0.001)$, in which no significant savings were observed ( $t=0.58, d f=7 ; P>0.5$; one-sample $t$-test).

Normalization again allowed interexperiment comparisons. In Experiment 3, performance in trial 2 (ca $45 \%$ of trial 1 path length) was slightly better than in Experiments 1 and 2, but the overall pattern shown across groups was comparable. Path length in trial 2 in the SCH23390/SCH23390 condition of Experiment 3 
A.

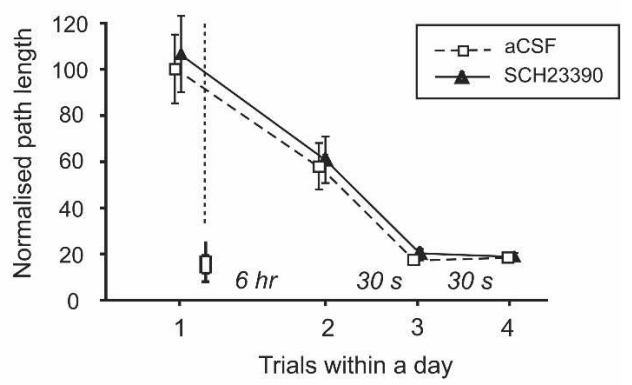

B.

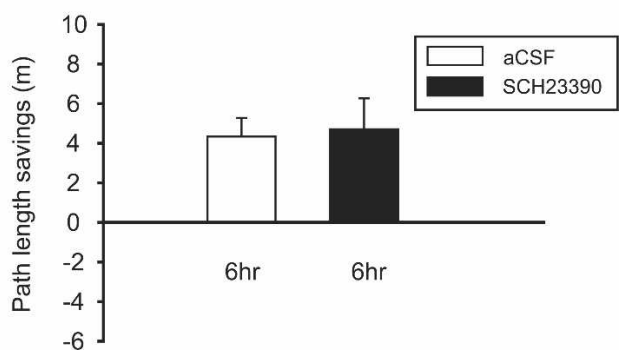

Figure 4. Experiment 2. (A) Drug injections after trial 1 (6-h memory delay). Normalized path length averaged across days during the druginfusion phase, showing performance across the four trials of each day $(n=8)$. No impairment is observed in the SCH23390 condition with the drug infusion occurring $15 \mathrm{~min}$ after trial 1 . (B) Savings in path length between trials 1 and 2 . The data show an equivalent level of absolute savings in path length in both conditions. Means \pm 1 SEM.

was $\cong 91 \%$ of that in trial 1 (compared with a $\cong 39 \%$ for the aCSF/ SCH23390 condition), a deficit of similar magnitude to that found in Experiment 1.

\section{Histology}

Cannulae were correctly placed within the dorsal hippocampal formation in all cases; a representative example of Nissl-stained brain sections is shown in Figure 6A. Infusion sites for all 39 rats tested in Experiments 1-3 are illustrated in Figure 6B, mapped onto successive coronal sections of the Paxinos and Watson (1998) atlas. The tips of all infusion cannulae were correctly located in the hippocampal formation.

\section{Discussion}

The main finding of these experiments is that bilateral intrahippocampal infusion of the D1/D5 receptor antagonist SCH23390 produced a delay-dependent impairment of spatial memory. There was a modest trend, but no significant impairment of memory after a short delay (20 min), arguing against a substantial contribution of dopaminergic activation to memory strength under the present circumstances, but a clear loss of spatial memory after $6 \mathrm{~h}$, implying an effect on persistence (Experiment 1). Moreover, the effect of SCH23390 on performance after the 6-h interval was specific to it being present during the encoding of the platform location during trial 1 , as no effects on performance after the 6-h interval were observed when the drug was infused after trial 1 (Experiment 2). The impairment seen at $6 \mathrm{~h}$ was not due to state dependency (Experiment 3) as a deficit was also seen if drug infusions occurred prior to both the encoding trial (trial 1) and the first memory retrieval trial (trial 2). The findings of Experiment 3 also replicate the delay-dependent effects of dopamine receptor blockade observed in Experiment 1: Long-term memory in trial 2 (6-h ITI) was impaired following an infusion of SCH23390 before trial 1, but short-term memory between trials 2 and 3 (30-sec ITI) was unimpaired following a second drug infusion before trial 2 .

Infusion of SCH23390: Dose, timing, and side effects The concentration of SCH23390 used in the present study (5 $\mu \mathrm{g}$ in $1 \mu \mathrm{L}$ ) was based on the highest dose infused into the prefrontal cortex in the study by Seamans et al. (1998), but is higher than concentrations typically infused intrahippocampally (e.g., Bernabeu et al. 1997) (maximum dose $=5 \mu \mathrm{g}$ per hippocampus). In the absence of microdialysis data (see Davis et al. 1992), it is difficult or impossible to estimate the effective hippocampal concentration of a drug following an acute intrahippocampal infusion. Accordingly, we cannot exclude the possibility that SCH23390 has agonist actions at 5-HT2a and c receptors at the concentration used (see Porter et al. 1999). However, the activation of these receptors has been implicated in the facilitation of hippocampusdependent memory (Buhot et al. 2000; Harvey 2003), in contrast to the findings reported here.

In the present study, drug infusion was associated with a very mild hypokinesia and a reduction in swim speed in trial 1 , but these effects were transient, dissipated rapidly, and were largely absent by trial 2 . A sensorimotor account of the effects of SCH23390 on retention performance is therefore unlikely. More tellingly, such an account would be inconsistent with our finding of better memory at a short delay after infusion before trial 1 (Experiment 1; 20-min memory delay), when the drug was most likely still present, compared with the impairment seen at the long delay (Experiment 1; 6-h memory delay). This argument is

A.

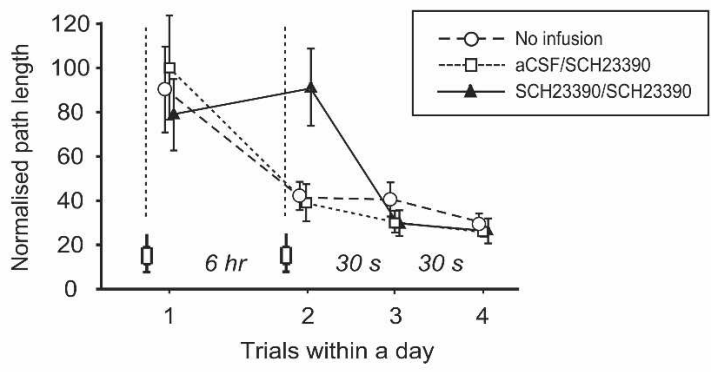

B.

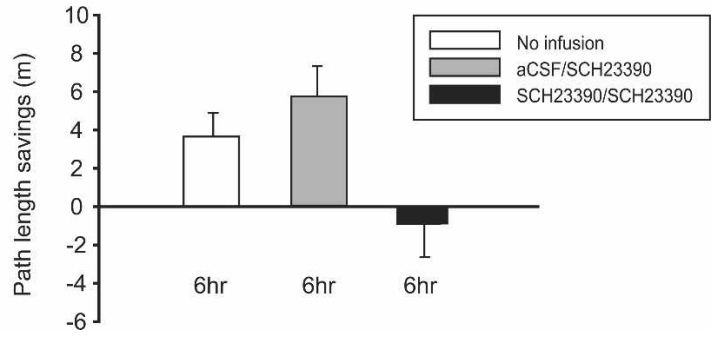

Figure 5. Experiment 3. (A) Drug injection prior to trials 1 and 2 (6-h memory delay). Normalized path length averaged across days during the drug-infusion phase, showing performance across the four trials of each day $(n=8)$. A clear interaction is apparent to the effect that memory in trial 2 is impaired when the drug is infused on two occasions each daybefore both trials 1 and 2 . Conversely, the group receiving aCSF initially, but drug later, showed good memory. The impairment in Experiment 1 cannot be due to state dependency. (B) Savings in path length between trials 1 and 2 . The same pattern is apparent in the absolute path-length data, with only the group having SCH23390 present at the time of encoding showing a memory deficit. Means \pm 1 SEM.

\section{Learning \& Memory}

www.learnmem.org 
A

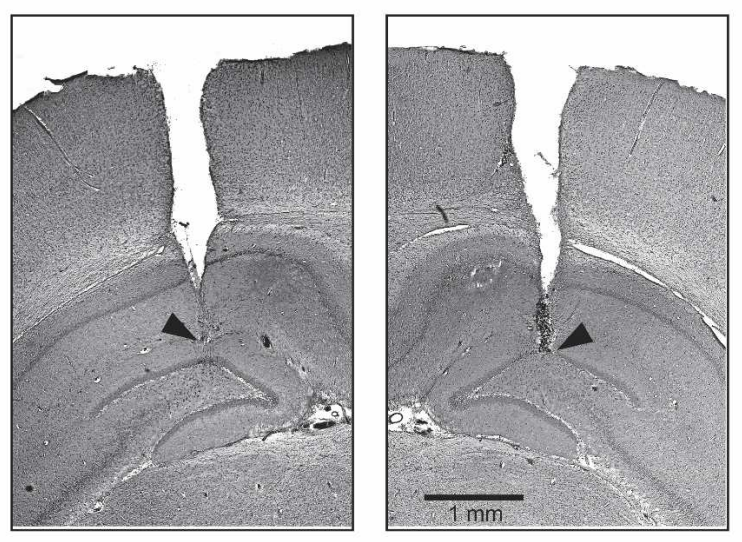

B

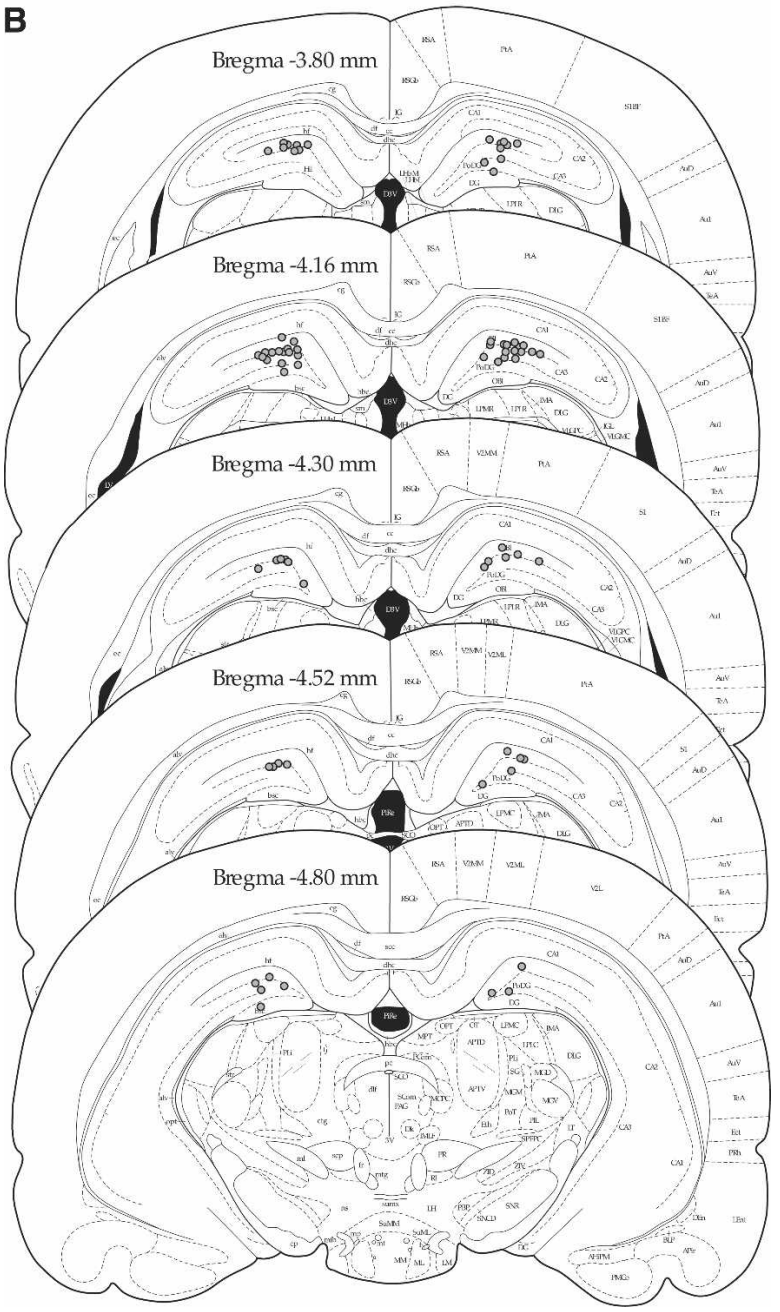

B

Figure 6. Histology. (A) Photomicrographs showing representative cannulae tracks into the dorsal hippocampus on each side of the brain. (B) Plots of the locations of the tips of the cannulae $(n=39$ per hippocampus) as revealed in Nissl-stained brain sections. Plots of the locations of the tips of the cannulae ( $n=39$ per hippocampus) as revealed in Nissl-stained brain sections. Infusion sites are marked on the appropriate section of a stereotaxic brain atlas (reprinted with permission from Elsevier ( 1998 , Paxinos and Watson 1998 [Figs. 35-39]). further supported by the absence of an impairment following drug infusion prior to retention testing in Experiment 3 when aCSF was given prior to trial 1 . Nonetheless, the differential effect of SCH23390 infused before or after trial 1 raises the possibility that the drug affects perceptual or attentional processes during encoding, rather than memory per se. However, the use of two different memory-delay intervals and the finding that the drug affects long-term but not short-term memory makes this unlikely; a disruption of such processes should cause a delayindependent impairment; this was not observed.

State-dependent learning is a phenomenon in which the retrieval of newly acquired information is facilitated if the subject is in the same sensory context and physiological state as that during the encoding phase (Overton 1964). By infusing animals just prior to both trial 1 and trial 2 in Experiment 3, we were also able to address the possibility that the animals trained with the 20-min ITI in Experiment 1 were still influenced by the drug in trial 2 and thus able, on state-dependent grounds, to perform well. The drug would have washed out in the 6-h condition, leaving the animals in a different physiological "state" during trial 2. The findings of Experiment 3 revealed that the only group of animals displaying poor retention was that infused twice with SCH23390. This is inconsistent with the effects being due to state-dependency.

It is interesting that the 6-h drug treatment condition exhibits such a marked improvement in performance between trials 2 and 3, with asymptotic performance reached after a single reexposure to the platform location. Although a failure of retrieval in trial 2 cannot be ruled out, this may not be the most likely explanation. First, a state-dependent failure of retrieval in trial 2 is ruled out by the results of Experiment 3. Second, it is possible that some time-limited effect of the drug infusion procedure, perhaps caused by stress or the change in context, might have impaired subsequent learning during trial 2 at the 20-min ITI. This might explain the poorer savings between trials 2 and 3 in both drug and aCSF conditions following the 20-min ITI, compared with the 6-h ITI. And in Experiment 3, when infusions were always given before trial 2 as well as trial 1, performance in trial 3 in the 6-h drug/drug-treated condition was no better than would be expected based on the one-trial improvement observed in the other conditions, and slightly worse than that observed in Experiment 1.

\section{Relationship of these findings to the synaptic tagging and capture hypothesis}

Long-term potentiation (LTP), an activity-dependent persistent increase in synaptic strength (Bliss and Lømo 1973), is the prevailing model of hippocampal learning-related synaptic plasticity, and the cornerstone of the generic "synaptic plasticity and memory" hypothesis. (Goelet et al. 1986; Bliss and Collingridge 1993; Martin et al. 2000; Martin and Morris 2002). However, an efficient memory system must retain relevant information selectively, while permitting the decay of irrelevant memory traces (McGaugh 2000). As discussed in the introduction, novelty has been implicated in the selection of hippocampal memory traces to be stored for long or short periods of time, but other factors such as stress and reward are also known to modulate hippocampal memory (McGaugh 2004; Wittmann et al. 2005; Adcock et al. 2006; Shors 2006), perhaps via their impact on synaptic plasticity (Seidenbecher et al. 1995, 1997; Xu et al. 1998b; Richter-Levin and Akirav 2003; Diamond et al. 2005; Korz and Frey 2005; Ahmed et al. 2006; Kavushansky et al. 2006). In one variant of this idea, the "synaptic tagging and capture" (STC) hypothesis (Frey and Morris 1997, 1998; Kelleher III et al. 2004), mechanisms underlying the persistence of LTP in the hippocampus involve the intersection of two dissociable events: the local set- 
ting of tags at activated glutamatergic synapses, followed by the sequestration of plasticity proteins newly synthesized in response to the activation of neuromodulatory inputs-and the subsequent activation of metabotropic cAMP-coupled receptors. Neuromodulatory inputs that regulate hippocampal synaptic plasticity include dopaminergic afferents to CA1 (see Introduction), noradrenergic inputs to the dentate gyrus (Straube et al. 2003; Harley 2004; Almaguer-Melian et al. 2005), and direct or indirect projections from other brain areas, such as the basolateral amygdala (Abe 2001; Frey et al. 2001; Almaguer-Melian et al. 2003; Richter-Levin and Akirav 2003; McGaugh 2004; Roozendaal et al. 2006). Once information is computed as novel or motivationally significant, feedback from neuromodulatory inputs such as those emanating from the VTA may rapidly influence the subsequent storage of such information. For example, Lisman and Otmakhova (2001) and Lisman and Grace (2005) suggest that synaptic plasticity following the exposure to and computation of novelty is critical to the formation of hippocampus-dependent memory.

Although there is some evidence that activation of hippocampal dopamine receptors with D1/D5 receptor agonists can alone be sufficient to induce late-LTP in hippocampal slices (Huang and Kandel 1995), more recent evidence points to the neuromodulatory effect that dopamine exerts on glutamateinduced events (Sajikumar and Frey 2004). Specifically, there is growing evidence for multilevel functional interactions between D1 and ionotropic glutamate receptors (e.g., Yang 2000; for review, see Cepeda and Levine 2006). It seems that the conditions necessary for "synaptic tagging" to occur require simultaneous coactivation of both D1/D5 and NMDA receptors to trigger the up-regulation of protein synthesis (O'Carroll and Morris 2004) or sufficient increases in intracellular cAMP concentrations through synergistic interaction between the two classes of receptor (Mockett et al. 2004). According to this view, the primary physiological impact of dopaminergic activity is not on the strength of potentiation directly, but in contributing to the triggering of cellular consolidation processes immediately after encoding (although effects on LTP magnitude should not be discounted) (see Li et al. 2003). These ideas are compatible with the Lisman and Grace (2005) model of VTA-hippocampal interactions, and are consistent with our observation that SCH23390 was only effective in blocking memory when given at the time of trial 1 . If SCH23390 blocked a chronic or constitutive effect of D1/D5 receptor activity on downstream signal-transduction pathways that enable memory persistence, its infusion 15 min after trial 1 might still have limited the persistence of memory. This was not observed. Such findings are also consistent with Kentros et al.'s (2004) data revealing opposite effects of a dopamine agonist (SKF38392) and antagonist (SCH23390) on place field stability, although interpreted by these investigators more in attentional terms. It may seem surprising that D1/D5 blockade as little as 15 min after trial 1 has no effect on memory, but this lack of effect is consistent with the need for dopamine/NMDA receptor interactions at the time of encoding, whether to affect spatial memory or place field stability. More direct evidence in support of the STC framework would include studies showing the induction of longterm memory during blockade of D1/D5 receptors if they had earlier been coactivated with glutamatergic afferent stimulation in the same neurons. Separate studies are underway to investigate this paradoxical prediction.

\section{"Novelty" may have multiple physiological consequences}

It is not yet clear what aspect of the rats' experience during trial 1 triggers the activation of dopamine receptors necessary for long-term memory formation. Relevant factors might include unexpected reward upon encountering the escape platform, an increase in arousal induced by immersion in water, or the experience of escape in a novel spatial location. Although its relevance to the present data remains uncertain, there is growing interest in the role of novelty in synaptic plasticity and memory. For example, exposure to novelty can facilitate the persistence of LTP as well as LTD-even in strains of rat in which LTD is normally difficult to observe (Manahan-Vaughan and Braunewell 1999; Kemp and Manahan-Vaughan 2004), an effect that is prevented by the administration of SCH23390 (Lemon and Manahan-Vaughan 2006). These findings are consistent with the effects of dopamine receptor activation on late-LTP and LTD (Sajikumar and Frey 2004), and support the notion that memory formation requires both down- and up-regulation of synaptic strength (Willshaw and Dayan 1990). Exploration of a novel environment can also reverse LTP that has been recently induced in freely moving animals (Xu et al. 1998a), perhaps owing to the novelty-associated increase in $\theta$ activity $(6-8 \mathrm{~Hz})$ in the hippocampus; an EEG pattern may supply the low-frequency stimulation necessary for depotentiation. However, the pharmacological activation of dopamine receptors has been reported to block depotentiation, a phenomenon that has been suggested to protect important memory traces from interference (Otmakhova and Lisman 1998; Kulla and Manahan-Vaughan 2000). In thinking about this apparent contradiction, it may be significant that different forms of novelty can influence synaptic plasticity in distinct ways (Kemp and Manahan-Vaughan 2004). To better understand the relationship between the present findings and the existing literature concerning novelty and the modulation of synaptic plasticity, further studies exploring the interactions between exposure to a novel platform location and the induction and persistence of synaptic changes will be required.

\section{Summary}

The present data suggest that the activation of hippocampal dopamine receptors is necessary for the formation of long-term spatial memory. We hypothesize that the firing of midbrain dopaminergic neurons-in response either to the unexpected reward or the spatial novelty of finding an escape platform in a new location-leads to hippocampal dopamine release and the activation of D1/D5 receptors in conjunction with the glutamatergic activation of NMDA receptors. The downstream consequences of this activity might include the up-regulation of protein synthesis, and the subsequent stabilization of synaptic changes at synapses "tagged" by glutamatergic stimulation. In the presence of a D1/D5 receptor antagonist, this selective stabilization mechanism would fail, resulting in the observed loss of long-term memory.

\section{Materials and Methods}

\section{Animals}

Adult male Lister hooded rats (250-500 g) were used as subjects. They were given ad libitum access to food and water and were maintained on a 12-h light/12-h dark cycle. The animals' care and maintenance and all experimental procedures were carried out in accordance with UK Home Office regulations under Project License no. 603241.

\section{Surgery}

Prior to the implantation of cannulae, the rats were anesthetized with Avertin (tribromoethanol) and placed in a stereotaxic frame (Kopf) using a flat skull position. Guide cannulae (Plastics One; outer diameter $=0.46 \mathrm{~mm}$ ) were implanted bilaterally into the dorsal hippocampus (coordinates from bregma: $\mathrm{AP}=-4.5$;

\section{Learning \& Memory \\ www.learnmem.org}


Lat. $=3.0 \mathrm{~mm}$; DV (from dura) $=-2.5 \mathrm{~mm}$ ). These were fixed in place using dental cement, and the headcap secured to the skull using jewelers' screws. To prevent blockage or infection, dummy cannulae (stylets; outer diameter $=0.20 \mathrm{~mm} ; 0.5-\mathrm{mm}$ protrusion from end of guide cannulae) were inserted into the guides. Postoperative analgesia was given (Rimadyl, $5 \mathrm{mg} / \mathrm{kg}$ by subcutaneous injection), and rats were given at least $7 \mathrm{~d}$ to recover before the start of behavioral testing.

\section{Watermaze}

Behavioral testing was carried out in an open-field watermaze, 2 $\mathrm{m}$ in diameter, and filled with water at $25 \pm 1{ }^{\circ} \mathrm{C}$ made opaque by the addition of $200 \mathrm{~mL}$ of latex solution. The pool was located in the center of a room containing prominent extramaze cues (poster, metal racks, etc.). The rats were placed into the water, facing the pool walls, and allowed to escape onto a hidden platform, $12 \mathrm{~cm}$ in diameter, whose top surface was submerged 1.5 $\mathrm{cm}$ below the water surface. The animals' swimming was monitored by an overhead video camera connected to a video recorder and a computer running custom-written Watermaze software (Actimetrics) that digitizes the path taken by the rat and computes various behavioral measures such as escape latency, path length, and swim speed.

\section{Pretraining}

In all experiments, rats were given $8 \mathrm{~d}$ of pretraining with four trials per day. The starting point for each trial was north, south, east, or west, varying in a quasirandom sequence, with rats placed gently into the water facing the side-walls. During pretraining, the hidden platform was located, on successive days, in one of eight possible locations within the pool. The platform location was changed between days according to a quasirandom schedule, and locations were never repeated (Fig. 1A). Each rat was randomly assigned to one of two counterbalanced platform location sequences, each of which was a mirror-image of the other. All trials ended with a 30-sec stay on the platform, during which the rat could turn, rear, and otherwise sample its location in space. After removal from the pool, the intertrial interval (ITI) between trials 1 and 2 was either 20 min or $6 \mathrm{~h}$ (see below); subsequent ITIs were always $15 \mathrm{sec}$.

\section{Drug preparation}

A total of $16 \mathrm{mg}$ of powdered SCH23390 was dissolved in $3.2 \mathrm{~mL}$ of sterile, millipore-filtered aCSF (in millimolar: $150 \mathrm{Na}^{+}, 3 \mathrm{~K}^{+}$, $1.4 \mathrm{Ca}^{2+}, 0.8 \mathrm{Mg}^{2+}, 155 \mathrm{Cl}^{-}, 0.2 \mathrm{H}_{2} \mathrm{PO}_{4}^{-}, 0.8 \mathrm{HPO}_{4}{ }^{2-}$, in pyrogen-free water at $\mathrm{pH} 7.2$ ) yielding a concentration of $5 \mathrm{mg} / \mathrm{mL}$ $(15.42 \mathrm{mM})$ This solution was vortexed and gently sonicated, divided into $500-\mu \mathrm{L}$ aliquots, and stored at $-20^{\circ} \mathrm{C}$ prior to use.

\section{Drug infusion}

Prior to daily infusions, the dummy cannulae were removed, and injection needles were inserted (outer diameter $=0.20 \mathrm{~mm}$ ). These protruded $0.5 \mathrm{~mm}$ from the ends of the guide cannulae (i.e., infusion site $=-3.0 \mathrm{~mm}$ from dura), and were connected via plastic tubing to SGE syringes mounted in a syringe driver. SCH23390 or aCSF $(1 \mu \mathrm{L} /$ side $)$ was infused at a rate of $0.2 \mu \mathrm{L} / \mathrm{min}$ over $5 \mathrm{~min}$, and the needles left in place for a further $2 \mathrm{~min}$ after infusion to avoid back-flow. Finally, the dummy cannulae were replaced.

\section{Experiment 1: Does SCH23390 infusion before encoding affect the persistence of memory?}

Following pretraining, 23 animals were tested over eight consecutive days with four trials per day, exactly as described for pretraining. The hidden platform was located, on successive days, in one of eight possible novel locations within the pool that differed from those used in pretraining. The memory delay between trials 1 and 2 was either $20 \mathrm{~min}$ or $6 \mathrm{~h}$, but always $30 \mathrm{sec}$ for the remaining trials. Across the $8 \mathrm{~d}$, there were four infusions of aCSF and four infusions of SCH23390, each lasting $5 \mathrm{~min}$, and finishing 15 min before trial 1 (Fig. 1B). Of the four infusions of each drug, two were made before a 20-min ITI, and two were made before a 6-h ITI. Drug treatments and ITIs were varied in a counterbalanced manner both within and across days, according to a partial Latin-square design.

\section{Experiment 2: Does $\mathrm{SCH} 23390$ infusion after encoding affect the persistence of memory?}

In Experiment 2, the memory delay between trials 1 and 2 was always $6 \mathrm{~h}$. The animals $(n=8)$ received $4 \mathrm{~d}$ of aCSF infusion and $4 \mathrm{~d}$ of SCH23390 infusion in a counterbalanced manner, with each 5-min infusion finishing $15 \mathrm{~min}$ after trial 1 (i.e., $5 \mathrm{~h}$ and 45 min prior to trial 2; Fig. 1B). In other respects, training was conducted as in Experiment 1.

\section{Experiment 3: Does SCH23390 infusion affect memory due to state dependency?}

In Experiment 3, the memory delay between trials 1 and 2 was again always $6 \mathrm{~h}$. Animals $(n=8)$ received a 5 -min intrahippocampal infusion of either aCSF or SCH23390, finishing 15 min before trial 1 of each day; a second infusion, always of SCH23390, finished $15 \mathrm{~min}$ prior to trial 2. After each infusion day, the animals were tested for a further day without receiving any injections. The drug and noninfusion conditions alternated, providing an internal within-subjects control for baseline performance on the task. These treatments continued for $8 \mathrm{~d}$ in a counterbalanced order, with a total of two SCH23390/SCH23390 days, two aCSF/SCH23390 days, and four no-infusion days for each rat. In all other respects, training was conducted as in Experiment 1.

\section{Histology}

At the end of the experiment, all animals were cardiac perfused with $0.9 \%$ saline followed by $10 \%$ formalin. Their brains were removed, placed in formalin, and $20-\mu \mathrm{m}$ sections were cut using a cryostat. These sections were stained using cresyl violet and examined under a light microscope. For each brain, the infusion site was plotted by determining the deepest point at which tissue damage was evident, and marking this location on the appropriate coronal section taken from the Paxinos and Watson (1998) atlas.

\section{Statistics}

All numerical data are presented as mean \pm SEM. Following an Analysis of Variance (ANOVA), pairwise comparisons were always conducted using Student's paired-sample t-test with Bonferroni correction for multiple comparisons, if appropriate. As described in the text, the main analyses were conducted using a measure of normalized path length that aided comparison across studies. Some data are also reported using escape latency (pretraining) and absolute savings in path length (all experiments).

\section{Acknowledgments}

This work was supported by a Volkswagen Grant to R.G.M.M. and J.U.F., and an MRC Grant held by R.G.M.M. and B.F., and formed part of a Ph.D. thesis submitted by C.O'C. We are grateful to Sharon Rossiter for assistance with drug infusions, Jane Tulloch for histology, and Patrick Spooner for advice on computing.

\section{References}

Abe, K. 2001. Modulation of hippocampal long-term potentiation by the amygdala: A synaptic mechanism linking emotion and memory. Ipn. J. Pharmacol. 86: 18-22.

Adcock, R.A., Thangavel, A., Whitfield-Gabrieli, S., Knutson, B., and Gabrieli, J.D.E. 2006. Reward-motivated learning: Mesolimbic activation precedes memory formation. Neuron 50: 507-517.

Aggleton, J.P. and Brown, M.W. 1999. Episodic memory, amnesia, and the hippocampal-anterior thalamic axis. Behav. Brain Sci. 22: $425-444$.

Ahmed, T., Frey, J.U., and Korz, V. 2006. Long-term effects of brief acute stress on cellular signalling and hippocampal LTP. J. Neurosci. 26: 3951-3958. 
Almaguer-Melian, W., Martinez-Marti, L., Frey, J.U., and Bergado, J.A. 2003. The amygdala is part of the behavioural reinforcement system modulating long-term potentiation in rat hippocampus. Neuroscience 119: 319-322.

Almaguer-Melian, W., Rojas-Reyes, Y., Alvare, A., Rosillo, J.C., Frey, J.U., and Bergado, J.A. 2005. Long-term potentiation in the dentate gyrus in freely moving rats is reinforced by intraventricular application of norepinephrine, but not oxotremorine. Neurobiol. Learn. Mem. 83: $72-78$.

Bach, M.E., Barad, M., Hyeon, S., Zhuo, M., Yun-Fei, L., Shih, R., Mansuy, I., Hawkins, R.D., and Kandel, E.R. 1999. Age-related defects in spatial memory are correlated with defects in the late phase of hippocampal long-term potentiation in vitro and are attenuated by drugs that enhance the cAMP signalling pathway. Proc. Natl. Acad. Sci. 96: 5280-5285.

Bernabeu, R., Bevilaqua, L., Ardenghi, P., Bromberg, E., Schmitz, P., Bianchin, M., Izquierdo, I., and Medina, J.H. 1997. Involvement of hippocampal cAMP/cAMP-dependent protein kinase signalling pathways in a late memory consolidation phase of aversively motivated learning in rats. Proc. Natl. Acad. Sci. USA 94: 7041-7046.

Bliss, T.V.P. and Collingridge, G.L. 1993. A synaptic model of memory: Long-term potentiation in the hippocampus. Nature 361: 31-39.

Bliss, T.V.P. and Lømo, T. 1973. Long-lasting potentiation of synaptic transmission in the dentate area of the anaesthetized rabbit following stimulation of the perforant path. J. Physiol. 232: 331-356.

Buhot, M.C., Martin, S., and Segu, L. 2000. Role of serotonin in memory impairment. Ann. Med. 32: 210-221.

Carter, D.A. and Fibiger, H.C. 1977. Ascending projections of presumed dopamine-containing neurons in the ventral tegmentum of the rat as demonstrated by horseradish peroxidase. Neuroscience 2: 569-576.

Cepeda, C. and Levine, M.S. 2006. Where do you think you are going? The NMDA-D1 receptor trap. Sci. STKE 333: pe20.

Davis, S., Butcher, S.P., and Morris, R.G. 1992. The NMDA receptor antagonist D-2-amino-5-phosphonopentanoate (D-AP5) impairs spatial learning and LTP in vivo at intracerebral concentrations comparable to those that block LTP in vitro. J. Neurosci. 12: 21-34.

Diamond, D.M., Park, C.R., Campbell, A.M., and Woodson, J.C. 2005. Competitive interactions between endogenous LTD and LTP underlie the storage of emotional memories and stress-induced amnesia. Hippocampus 15: 1006-1025.

Dudai, Y. and Morris, R.G.M. 2001. To consolidate or not to consolidate: What are the questions? In Brain, perception, memory. Advances in cognitive sciences (ed. J.J. Bolhuis). Oxford University Press, Oxford, UK.

El-Ghundi, M., Fletcher, P.J., Drago, J., Sibley, D.R., O’Dowd, B.F., and George, S.R. 1999. Spatial learning deficit in D1 receptor knockout mice. Eur. J. Pharmacol. 383: 95-106.

Frey, U. and Morris, R.G.M. 1997. Synaptic tagging and long-term potentiation. Nature 385: 533-536.

Frey, U. and Morris, R.G.M. 1998. Synaptic tagging: Implications for late maintenance of hippocampal long-term potentiation. Trends Neurosci. 21: 181-188.

Frey, U., Schroeder, H., and Matthies, H. 1990. Dopaminergic antagonists prevent long-term maintenance of posttetanic LTP in the CA1 region of rat hippocampal slices. Brain Res. 522: 69-75.

Frey, U., Matthies, H., Reymann, K.G., and Matthies, H. 1991. The effect of dopaminergic D1 receptor blockade during tetanization on the expression of long-term potentiation in the rat CA1 region in vitro. Neurosci. Lett. 129: 111-114.

Frey, S., Bergado-Rosado, J., Seidenbecher, T., Pape, H.C., and Frey, J.U. 2001. Reinforcement of early long-term potentiation (early-LTP) in dentate gyrus by stimulation of the basolateral amygdala: Heterosynaptic induction mechanisms of late-LTP. J. Neurosci. 21: 3697-3703.

Fyhn, M., Molden, S., Hollup, S., Moser, M.-B., and Moser, E. 2002. Hippocampal neurons responding to first-time dislocation of a target object. Neuron 35: 555-566.

Gasbarri, A., Packard, M.G., Campana, E., and Pacitti, C. 1994a. Anterograde and retrograde tracing of projections from the ventral tegmental area to the hippocampal formation in the rat. Brain Res. Bull. 33: 445-452.

Gasbarri, A., Verney, C., Innocenzi, R., Campana, E., and Pacitti, C. 1994b. Mesolimbic dopaminergic neurons innervating the hippocampal formation in the rat: A combined retrograde tracing and immunohistochemical study. Brain Res. 668: 71-79.

Gasbarri, A., Sulli, R., Innocenzi, C., Pacitti, C., and Brioni, J.D. 1996. Spatial memory impairment induced by lesion of the mesencephalic dopaminergic system in the rat. Neuroscience 74: 1037-1044.

Gasbarri, A., Sulli, A., and Packard, M.G. 1997. The dopaminergic mesencephalic projections to the hippocampal formation in the rat. Prog. Neuropsychopharmacol. Biol. Psychiatry 21: 1-22.

Goelet, P., Castellucci, V.F., Schacher, S., and Kandel, E.R. 1986. The long and the short of long-term memory-a molecular framework. Nature 322: 419-422.

Gray, J.A. and McNaughton, N. 2000. The neuropsychology of anxiety: An enquiry into the functions of the septo-hippocampal system, 2 nd ed. Oxford University Press, Oxford, UK.

Hagan, J.J., Alpert, J., Morris, R.G.M., and Iversen, S.D. 1983. The effects of catecholamine depletion upon spatial memory in rats. Behav. Brain Res. 9: 83-104.

Harley, C.W. 2004. Norepinephrine and dopamine as learning signals. Neural Plast. 11: 191-204.

Harvey, J.A. 2003. Role of the 5-HT(2A) receptor in learning. Learn. Mem. 10: $355-362$.

Huang, Y.Y. and Kandel, E.R. 1995. D1/D5 receptor agonists induce a protein synthesis-dependent late potentiation in the CA1 region of the hippocampus. Proc. Natl. Acad. Sci. 92: 2446-2450.

Jay, T.M. 2003. Dopamine: A potential substrate for synaptic plasticity and memory mechanisms. Prog. Neurobiol. 69: 375-390.

Kavushansky, A., Vouimba, R.M., Cohen, H., and Richter-Levin, G. 2006. Activity and plasticity in the CA1, the dentate gyrus, and the amygdala following controllable vs. uncontrollable water stress. Hippocampus 16: $35-42$.

Kelleher III, R.J., Govindarajan, A., and Tonegawa, S. 2004. Translational regulatory mechanisms in persistent forms of synaptic plasticity. Neuron 44: 59-73.

Kemp, A. and Manahan-Vaughan, D. 2004. Hippocampal long-term depression and long-term potentiation encode different aspects of novelty acquisition. Proc. Natl. Acad. Sci. 101: 8192-8197.

Kentros, C.G., Agnihotri, N.T., Streater, S., Hawkins, R.D., and Kandel, E.R. 2004. Increased attention to spatial context increases both place field stability and spatial memory. Neuron 42: 283-295.

Korz, V. and Frey, J.U. 2005. Bidirectional modulation of hippocampal long-term potentiation under stress and no-stress conditions in basolateral amygdala-lesioned and intact rats. J. Neurosci. 25: 7393-7400.

Kulla, A. and Manahan-Vaughan, D. 2000. Depotentiation in the dentate gyrus of freely moving rats is modulated by D1/D5 receptors. Cereb. Cortex 10: 614-620.

Kusuki, T., Imahori, Y., Ueda, S., and Inokuchi, K. 1997. Dopaminergic modulation of LTP induction in the dentate gyrus of intact brain. Neuroreport 8: 2037-2040.

Lemon, N. and Manahan-Vaughan, D. 2006. Dopamine D1/D5 receptors gate the acquisition of novel information through hippocampal long-term potentiation and long-term depression. J. Neurosci. 26: 7723-7729.

Li, S., Cullen, W.K., Anwyl, R., and Rowan, M.J. 2003. Dopamine-dependent facilitation of LTP induction in hippocampal CA1 by exposure to spatial novelty. Nat. Neurosci. 6: 526-531.

Lisman, J.E. and Grace, A.A. 2005. The hippocampal-VTA loop: Controlling the entry of information into long-term memory. Neuron 46: 703-713.

Lisman, J.E. and Otmakhova, N.A. 2001. Storage, recall, and novelty detection of sequences by the hippocampus: Elaborating on the SOCRATIC model to account for normal and aberrant effects of dopamine. Hippocampus 11: 551-568.

Ljungberg, T., Apicella, P., and Schultz, W. 1992. Responses of monkey dopamine neurons during learning of behavioral reactions. $J$. Neurophysiol. 67: 145-163.

Manahan-Vaughan, D. and Braunewell, K.H. 1999. Novelty acquisition is associated with induction of hippocampal long-term depression. Proc. Natl. Acad. Sci. 96: 8739-8744.

Martin, S.J. and Morris, R.G.M. 2002. New life in an old idea: The synaptic plasticity and memory hypothesis revisited. Hippocampus 12: 609-636.

Martin, S.J., Grimwood, P.D., and Morris, R.G.M. 2000. Synaptic plasticity and memory: An evaluation of the hypothesis. Annu. Rev. Neurosci. 23: 649-711.

Matthies, H., Becker, A., Schroeder, H., Kraus, J., Hollt, V., and Krug, M. 1997. Dopamine D1-deficient mutant mice do not express the late phase of hippocampal long-term potentiation. Neuroreport 8: $3533-3535$.

McGaugh, J.L. 2000. A century of consolidation. Science 287: 248-251.

McGaugh, J.L. 2004. The amygdala modulates the consolidation of memories of emotionally arousing experiences. Annu. Rev. Neurosci. 27: $1-28$.

Mirenowicz, J. and Schultz, W. 1994. Importance of unpredictability for reward responses in primate dopamine neurons. J. Neurophysiol. 72: 1024-1027

Mockett, B.G., Brooks, W.M., Tate, W.P., and Abraham, W.C. 2004. Dopamine D1/D5 receptor activation fails to initiate an activity-independent late-phase LTP in rat hippocampus. Brain Res. 1021: $92-100$.

Montague, P.R., Dayan, P., and Sejnowski, T.J. 1996. A framework for 
mesencephalic dopamine systems based on predictive Hebbian learning. J. Neurosci. 16: 1936-1947.

O'Carroll, C.M. and Morris, R.G.M. 2004. Heterosynaptic co-activation of glutamatergic and dopaminergic afferents is required to induce persistent long-term potentiation. Neuropharmacology 47: 324-332.

Otmakhova, N.A. and Lisman, J.E. 1996. D1/D5 dopamine receptor activation increases the magnitude of early long-term potentiation at CA1 hippocampal synapses. J. Neurosci. 16: 7478-7486.

Otmakhova, N.A. and Lisman, J.E. 1998. D1/D5 dopamine receptors inhibit depotentiation at CA1 synapses via cAMP-dependent mechanism. J. Neurosci. 18: 1270-1279.

Overton, D.A. 1964. State dependent or "dissociated" learning produced with pentobarbital. J. Comp. Physiol. Psychol. 57: 3-12.

Packard, M.G. and White, N.M. 1991. Dissociation of hippocampus and caudate nucleus memory systems by posttraining intracerebral injection of dopamine agonists. Behav. Neurosci. 105: 295-306.

Paxinos, G. and Watson, C. 1998. The rat brain in stereotaxic coordinates. Academic Press, NY.

Porter, R.H.P., Benwell, K.R., Lamb, H., Malcolm, C.S., Allen, N.H., Revell, D.F., Adams, D.R., and Sheardown, M.J. 1999. Functional characterization of agonists at recombinant human 5HT-2A, 5-HT2B and 5-HT2C receptors in CHO-K1 cells. Br. J. Pharmacol. 128: 13-20.

Richter-Levin, G. and Akirav, I. 2003. Emotional tagging of memory formation-in the search for neural mechanisms. Brain Res. Brain Res. Rev. 43: 247-256.

Roozendaal, B., Okuda, S., Van der Zee, E.A., and McGaugh, J.L. 2006. Glucocorticoid enhancement of memory requires arousal-induced noradrenergic activation in the basolateral amygdala. Proc. Natl. Acad. Sci. 103: 6741-6746.

Sajikumar, S. and Frey, J.U. 2004. Late-associativity, synaptic tagging, and the role of dopamine during LTP and LTD. Neurobiol. Learn. Mem. 82: 12-25.

Scatton, B., Simon, H., Le Moal, M., and Bischoff, S. 1980. Origin of dopaminergic innervation of the rat hippocampal formation. Neurosci. Lett. 18: 125-131.

Schultz, W. and Dickinson, A. 2000. Neuronal coding of prediction errors. Annu. Rev. Neurosci. 23: 473-500.

Seamans, J.K., Floresco, S.B., and Phillips, A.G. 1998. D1 receptor modulation of hippocampal-prefrontal cortical circuits integrating spatial memory with executive functions in the rat. J. Neurosci. 18: $1613-1621$.

Seidenbecher, T., Balschun, D., and Reymann, K.G. 1995. Drinking after water deprivation prolongs "unsaturated" LTP in the dentate gyrus of rats. Physiol. Behav. 57: 1001-1004.

Seidenbecher, T., Reymann, K.G., and Balschun, D. 1997. A post-tetanic time window for the reinforcement of long-term potentiation by appetitive and aversive stimuli. Proc. Natl. Acad. Sci. 94: 1494-1499.

Shors, T. 2006. Stressful experience and learning across the lifespan. Annu. Rev. Psychol. 57: 55-85.

Smith, W., Starck, S., Roberts, R., and Schuman, E. 2005. Dopaminergic stimulation of local protein synthesis enhances surface expression of GluR1 and synaptic transmission in hippocampal neurons. Neuron 45: $765-779$.

Steele, R.J. and Morris, R.G.M. 1999. Delay-dependent impairment of a matching-to-place task with chronic and intrahippocampal infusion of the NMDA-antagonist D-AP5. Hippocampus 9: 118-136.

Steinfels, G.F., Heym, J., Strecker, R.E., and Jacobs, B.L. 1983. Response of dopaminergic neurons in cat to auditory stimuli presented across the sleep-waking cycle. Brain Res. 277: 150-154.

Straube, T., Korz, V., and Frey, J.U. 2003. Bidirectional modulation of long-term potentiation by novelty-exploration in rat dentate gyrus. Neurosci. Lett. 344: 5-8.

Swanson, L.W. 1982. The projections of the ventral tegmental area and adjacent regions: A combined fluorescent retrograde tracer and immunofluorescence study in the rat. Brain Res. Bull. 9: 321-353.

Swanson-Park, J.L., Coussens, C.M., Mason-Parker, S.E., Raymond, C.R., Hargreaves, E.L., Dragunow, M., Cohen, A.S., and Abraham, W.C. 1999. A double dissociation within the hippocampus of dopamine D1/D5 receptor and $\beta$-adrenergic receptor contributions to the persistence of long-term potentiation. Neuroscience 92: 485-497.

Thinus-Blanc, C., Save, E., Poucet, B., and Buhot, M.C. 1991. The effects of reversible inactivations of the hippocampus on exploratory activity and spatial memory. Hippocampus 1: 365-371.

Tulving, E., Markowitsch, H.J., Kapur, S., Habib, R., and Houle, S. 1994. Novelty encoding networks in the human brain: Positron emission tomography data. Neuroreport 5: 2525-2528.

Vinogradova, O.S. 2001. Hippocampus as comparator: Role of the two input and two output systems of the hippocampus in selection and registration of information. Hippocampus 11: 578-598.

Whishaw, I.Q. and Dunnett, S.B. 1985. Dopamine depletion, stimulation or blockade in the rat disrupts spatial navigation and locomotion dependent upon beacon or distal cues. Behav. Brain Res. 18: $11-29$.

Wilkerson, A. and Levine, E.D. 1999. Ventral and hippocampal dopamine D1 and D2 systems and spatial working memory in rats. Neuroscience 89: 743-749.

Willshaw, D. and Dayan, P. 1990. Optimal plasticity from matrix memories: What goes up must come down. Neural Comput. 2: 85-93.

Wittmann, B.C., Schott, B.H., Guderian, S., Frey, J.U., Heinze, H.J., and Duzel, E. 2005. Reward-related fMRI activation of dopaminergic midbrain is associated with enhanced hippocampus-dependent long-term memory formation. Neuron 45: 459-467.

Xu, L., Anwyl, R., and Rowan, M.J. 1998a. Spatial exploration induces a persistent reversal of long-term potentiation in rat hippocampus. Nature 394: 891-894.

Xu, L., Holscher, C., Anwyl, R., and Rowan, M.J. 1998b. Glucocorticoid receptor and protein/RNA synthesis-dependent mechanisms underlie the control of synaptic plasticity by stress. Proc. Natl. Acad. Sci. 95: 3204-3208.

Yang, S.N. 2000. Sustained enhancement of AMPA receptor- and NMDA receptor-mediated currents induced by dopamine D1/D5 receptor activation in the hippocampus: An essential role of postsynaptic $\mathrm{Ca}^{2+}$. Hippocampus 10: $57-63$.

Received May 16, 2006; accepted in revised form August 30, 2006. 


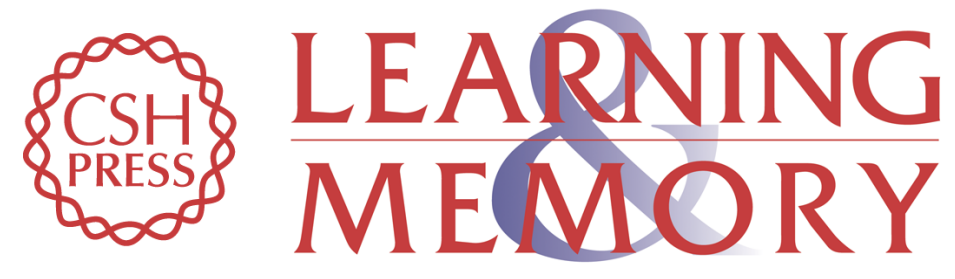

\section{Dopaminergic modulation of the persistence of one-trial hippocampus-dependent memory}

Colin M. O'Carroll, Stephen J. Martin, Johan Sandin, et al.

Learn. Mem. 2006, 13:

Access the most recent version at doi:10.1101//m.321006

References This article cites 84 articles, 19 of which can be accessed free at: http://learnmem.cshlp.org/content/13/6/760.full.html\#ref-list-1

License

Email Alerting Receive free email alerts when new articles cite this article - sign up in the box at the Service top right corner of the article or click here. 